\title{
Exercise Testing in Idiopathic Pulmonary Fibrosis: Expanding Our Options
}

\author{
Marco Mura ${ }^{a}$ Demosthenes Bouros ${ }^{b}$ \\ ${ }^{a}$ Division of Respirology. Western University, London, ON, Canada; ${ }^{b}$ First Academic Department of Pneumonology, \\ Medical School, National and Kapodistrian University of Athens, and Athens Medical Center, Athens, Greece
}

One of the foremost consequences of idiopathic pulmonary fibrosis (IPF) is a striking compromisation of the patient's exercise capacity, which severely affects the quality of life on an everyday basis [1]. IPF and fibrosing interstitial lung diseases (ILDs) in general are known to cause exchange and ventilatory impairments, increased dead space ventilation, insufficient increase in heart rate during exercise, peripheral muscle dysfunction, and increased elastic inspiratory load [2-5]. A complex interaction of these factors is likely at the bases of the exercise intolerance often seen in IPF.

Clinicians have long learned that this is not only important to recognize and address this deficiency with physiotherapy retraining, but measuring its severity has also a relevant impact on clinical monitoring and prognostication [6]. While cardiopulmonary exercise testing (CPET) remains the most physiologically comprehensive exercise test in patients with chronic lung disease, the 6 -min walk test (6MWT) has become the most used tool to test exercise capacity in IPF and other fibrosing ILDs. The wide adoption of the 6MWT was justified by its reliability, reproducibility, safety, and reduced cost [7]. The observation that 6-min walk distance (6MWD) results correlated well with those of CPET [8] was particularly reassuring for clinicians.

karger@karger.com

(c) 2021 S. Karger AG, Basel

www.karger.com/res

Karger
Importantly, 6MWD has been recognized as an independent predictor of survival in IPF and as a feasible endpoint in clinical trials [9]. Another fundamental finding was that $6 \mathrm{MWD}$ provides prognostic information that is complementary to that provided by pulmonary function tests (PFTs) $[10,11]$. Some data have shown that 6MWD may be even superior to PFTs in terms of accuracy of survival prediction in IPF [12].

Being self-limited, the $6 \mathrm{MWT}$ is also an inherently safe test that can be applied even in advanced stages of the disease. Minimal clinically significant differences specific for IPF were identified $[8,13,14]$.

Notwithstanding all these positive aspects, every pulmonary specialist managing patients with IPF and ILDs in general has probably experienced that it is challenging to obtain a $6 \mathrm{MWT}$ at every visit for every single patient, due to logistical difficulties and limitations in the pulmonary function laboratories. The 6MWT is in fact somewhat time-consuming, especially if coupled with a full set of PFTs, and requires a dedicated space. This problem can limit the clinical applicability of the 6MWT in most settings.

In this issue of respiration, Degano et al. [15] present their study on sit-to-stand tests (STSTs) in a cohort of 33 patients with IPF from 3 different French referral centers. 
Both a 1-min STST and 3-min chair rise test were considered, together with the standard 6MWT. Patients performed the 3 tests sequentially. Based on the simple movement of standing up from a chair, STSTs are exercises designed to test leg strength, endurance as well as independence in adults [16]. STSTs were first introduced in 1985 [17] and have been already extensively studied in chronic obstructive pulmonary disease [18].

The main findings were that STSTs in IPF had very good reproducibility, when repeated at a 7-14 days distance, and their results showed a strong correlation with $6 \mathrm{MWD}$. However, the extent of desaturation seen during the 6MWT was not fully captured by STSTs.

STSTs reproduce a key element of everyday activity [16] but received little attention in ILDs. In their elegant study, Degano et al. demonstrated the potential clinical applicability of short and simple tests of vertical displacement in patients with IPF. STSTs are well suit to capture the extent of sarcopenia, a common feature of patients with IPF that is now recognized to be a significant predictor of survival [19].

It is now ascertained that exercise capacity is a fundamental component of the prognostic assessment of patients with chronic lung disease, including IPF [9-11]. Although STSTs tests may not fully capture the depth of desaturation seen with the 6MWT in subjects with IPF, they may nevertheless expand our options of exercise testing in fibrosing ILDs. From this perspective, the study of Degano et al.[21]sets an interesting framework of re- search: can STSTs represent a surrogate exercise test for $6 \mathrm{MWT}$ to monitor the clinical course of the disease? Can the present results be applied to a wider range of ILDs? Can STSTs capture the significant impact of associated pulmonary hypertension on exercise capacity in fibrosing ILDs [20] [21]?

We, therefore, look forward to further studies applied to a larger cohort of patients with IPF longitudinally followed to investigate the prognostic role of STSTs. Identifying a simple, inexpensive, and reproducible measure of exercise capacity that is prognostically complementary to the information provided by PFTs represents a research priority in IPF and fibrosing ILD in general.

\section{Conflict of Interest Statement}

The authors have no conflicts of interest to declare.

\section{Funding Sources}

No funding was received.

\section{Author Contributions}

Marco Mura: manuscript drafting. Demosthenes Bouros: manuscript drafting.

\section{References}

1 Bahmer T, Kirsten AM, Waschki B, Rabe KF, Magnussen $\mathrm{H}$, Kirsten D, et al. Clinical correlates of reduced physical activity in idiopathic pulmonary fibrosis. Respiration. 2016; 91(6):497-502.

2 Miki K, Maekura R, Hiraga T, Okuda Y, Okamoto T, Hirotani A, et al. Impairments and prognostic factors for survival in patients with idiopathic pulmonary fibrosis. Respir Med. 2003;97(5):482-90.

3 Chetta A, Marangio E, Olivieri D. Pulmonary function testing in interstitial lung diseases. Respiration. 2004;71(3):209-13.

4 Leblanc P, Bowie DM, Summers E, Jones NL, Killian KJ. Breathlessness and exercise in patients with cardiorespiratory disease. Am Rev Respir Dis. 1986;133(1):21-5.

5 Tzilas V, Bouros D. Cardiopulmonary exercise testing in systemic sclerosis: ars longa, vita brevis. Respiration. 2016;91(3):202-3.
6 Wuyts WA, Wijsenbeek M, Bondue B, Bouros D, Bresser P, Robalo Cordeiro C, et al. Idiopathic pulmonary fibrosis: best practice in monitoring and managing a relentless fibrotic disease. Respiration. 2020;99(1):73-82.

7 ATS Committee on Proficiency Standards for Clinical Pulmonary Function Laboratories. ATS statement: guidelines for the six-minute walk test. Am J Respir Crit Care Med. 2002; 166(1):111-7.

8 Eaton T, Young P, Milne D, Wells AU. Sixminute walk, maximal exercise tests: reproducibility in fibrotic interstitial pneumonia. Am J Respir Crit Care Med. 2005;171(10): $1150-7$.

9 du Bois RM, Weycker D, Albera C, Bradford WZ, Costabel U, Kartashov A, et al. Six-minute-walk test in idiopathic pulmonary fibrosis: test validation and minimal clinically important difference. Am J Respir Crit Care Med. 2011;183(9):1231-7.
10 du Bois RM, Albera C, Bradford WZ, Costabel U, Leff JA, Noble PW, et al. Six-minute walk distance is an independent predictor of mortality in patients with idiopathic pulmonary fibrosis. Eur Respir J. 2014;43(5):1421-9.

11 Serajeddini H, Rogliani P, Mura M. Multi-dimensional assessment of IPF across a wide range of disease severity. Lung. 2018;196(6): 707-13.

12 Pesonen I, Gao J, Kalafatis D, Carlson L, Sköld M, Ferrara G. Six-minute walking test outweighs other predictors of mortality in idiopathic pulmonary fibrosis. A real-life study from the Swedish IPF registry. Respir Med. 2020;2:100017.

13 Nathan SD, du Bois RM, Albera C, Bradford WZ, Costabel U, Kartashov A, et al. Validation of test performance characteristics and minimal clinically important difference of the 6-minute walk test in patients with idiopathic pulmonary fibrosis. Respir Med. 2015;109(7):914-22. 
14 Tzilas V, Bouros D. The six-minute stepper test: solvitur ambulando. Respiration. 2016; 91(6):469-70.

15 Degano B, Fedi A, Keddache A, Quetant S, Guillien A, Antoniadis A, et al. Concurrence of 1- and 3-min sit-to-stand tests with the 6-min walk test in idiopathic pulmonary fibrosis. Respiration, DOI: 10.1159/000515335.

16 Bohannon RW. Daily sit-to-stands performed by adults: a systematic review. J Phys Ther Sci. 2015;27(3):939-42.
17 Csuka M, McCarty DJ. Simple method for measurement of lower extremity muscle strength. Am J Med. 1985;78(1):77-81.

18 Vaidya T, Chambellan A, de Bisschop C. Sitto-stand tests for COPD: a literature review. Respir Med. 2017;128:70-7.

19 Rinaldi S, Gilliland J, O'Connor C, Seabrook JA, Mura M, Madill J, et al. Fat-free mass index controlled for age and sex, and malnutrition are predictors of survival in interstitial lung disease. Respiration. 2021 Mar;15;1-8.
20 Pitsiou G, Papakosta D, Bouros D. Pulmonary hypertension in idiopathic pulmonary fibrosis: a review. Respiration. 2011;82(3):294304.

21 Yoo DK, Zompatori M, Barrile A, Rossi G, D'Amato D, Sergiacomi G, et al. Associated pulmonary hypertension is an independent contributor to exercise intolerance in chronic fibrosing interstitial pneumonias. Respiration. 2018;96(6):543-51. 